\title{
Efficacy of 4 Irrigation Protocols in Killing Bacteria Colonized in Dentinal Tubules Examined by a Novel Confocal Laser Scanning Microscope Analysis
}

\author{
Adbam A. Azim, BDS, ${ }^{*^{1}}$ Hacer Aksel, DDS, ${ }^{*}$ Tingting Zhuang, MA, ${ }^{\dagger}$ Terry Mashtare, PhD, ${ }^{\dagger}$ \\ Jegdish P. Babu, PbD, * and George T.-J. Huang, DDS, MSD, DSc*
}

\begin{abstract}
Ahstract
Introduction: The aim of this study was to determine the efficiency of 4 irrigation systems in eliminating bacteria in root canals, particularly in dentinal tubules. Methods: Roots of human teeth were prepared to 25/ 04, autoclaved, and inoculated with Enterococcus faecalis for 3 weeks. Canals were then disinfected by (1) standard needle irrigation, (2) sonically agitating with EndoActivator, (3) XP Endo finisher, or (4) erbium:yttrium aluminum garnet laser (PIPS) (15 roots/ group). The bacterial reduction in the canal was determined by MTT assays. For measuring live versus dead bacteria in the dentinal tubules (4 teeth/group), teeth were split open and stained with LIVE/DEAD BackLight. Coronal, middle, and apical thirds of the canal dentin were scanned by using a confocal laser scanning microscope (CLSM) to determine the ratio of dead/total bacteria in the dentinal tubules at various depths. Results: All 4 irrigation protocols significantly eliminated bacteria in the canal, ranging from $89.6 \%$ to 98.2\% reduction $(P<.001)$. XP Endo had the greatest bacterial reduction compared with other 3 techniques $(P<.05)$. CLSM analysis showed that XP Endo had the highest level of dead bacteria in the coronal, middle, and apical segments at $50-\mu \mathrm{m}$ depth. On the other hand, PIPS had the greatest bacterial killing efficiency at the $150-\mu \mathrm{m}$ depth in all 3 root segments. Conclusions: XP Endo appears to be more efficient than other 3 techniques in disinfecting the main canal space and up to $50 \mu \mathrm{m}$ deep into the dentinal tubules. PIPS appears to be most effective in killing the bacteria deep in the dentinal tubules. (J Endod 2016;42:928-934)
\end{abstract}

\section{Key Words}

CLSM, dentinal tubules, EndoActivator, MTT assay, PIPS, root canal disinfection, XP Endo

The he main goal of chemomechanical treatment of the root canal system is to eliminate or reduce bacterial populations in the canal to a level that can allow periradicular tissue healing with a positive treatment outcome (1-3). To render the canal bacteriafree is challenging. Mechanical debridement alone is limited in reaching all the root canal spaces $(4,5)$. Previous studies have demonstrated that only $40 \%-60 \%$ of the cases can have a negative culture after cleaning and shaping of the canals (6-10). Recent endeavors on advancing regenerative endodontics further underscore the importance of effective root canal disinfection (11). Thus, strategies for root canal disinfection should be directed to use more effective irrigation activation techniques that may maximize root canal disinfection. Multiple activation methods have been proposed to improve the efficacy of irrigants, including sonic, ultrasonic, negative apical pressure irrigation, as well as laser activation (12).

EndoActivator (EA) (Dentsply, York, PA) is a battery-operated sonic handpiece that uses plastic tips to agitate irrigant solutions vigorously. The activator tips are available in 3 different sizes and produce $2000-10,000$ cycles/min. It is recommended to use after cleaning and shaping of the root canal system to activate the irrigation solution (13). Photon-induced photoacoustic streaming (PIPS) has been recently introduced and gained attention because of its properties that appear to enhance the disinfection of the root canal system (14-16). PIPS operates by transferring the energy to the irrigation molecules, resulting in rapid and powerful shock waves, forcing the irrigant throughout the entire root canal system (17). XP Endo Finisher (FKG Dentaire, Switzerland) is also a new file that has been recently introduced to be used as a final disinfection step to disturb the bacterial biofilm. It is claimed by the manufacturer to provide an optimal cleaning of the root canal system while preserving dentin.

The effectiveness of multiple irrigation techniques on reducing the bacterial count in the main root canal space has been previously investigated $(18,19)$. More recent studies have visualized bacteria in dentinal tubules and determined its status (live or dead) by confocal laser scanning microscopy (CLSM) (14, 20). Zou et al (21) have shown that NaOCl can penetrate into the dentinal tubules

From the *Department of Bioscience Research, College of Dentistry, University of Tennessee Health Science Center, Memphis, Tennessee; and ${ }^{\dagger}$ Department of Biostatistics, University at Buffalo School of Public Health and Health Professions, Buffalo, New York.

${ }^{1}$ Current address: Adham A. Azim, Department of Periodontics and Endodontics, University at Buffalo School of Dental Medicine, Buffalo, New York

${ }^{2}$ Current address: Hacer Aksel, Department of Endodontics, School of Dentistry, Hacettepe University, Ankara, Turkey

Address requests for reprints to Dr George T.-J. Huang, Department of Bioscience Research, College of Dentistry, University of Tennessee Health Science Center, 875 Union Avenue, Memphis, TN 38163. E-mail address: gtjhuang@uthsc.edu

0099-2399/\$ - see front matter

Copyright () 2016 American Association of Endodontists.

http://dx.doi.org/10.1016/j.joen.2016.03.009 
at a range between 77 and $300 \mu \mathrm{m}$, depending on time, concentration, and temperature. There is a lack of studies providing quantitative assessment for the level of bacterial reduction in the dentinal tubules after disinfection. Therefore, the aim of this study was to quantify and compare the bacterial viability in root canals treated by 4 different irrigation systems: standard needle irrigation (SNI), EA, XP Endo, and PIPS. We measured the level of bacterial reduction in the main canal by using a chemical method and in the dentinal tubules by using CLSM analysis.

\section{Specimen Preparation}

\section{Materials and Methods}

Intact mandibular premolars and molars with no apical resorption were collected from the clinic in the Department of Oral and Maxillofacial Surgery and placed in phosphate-buffered solution (PBS). The tooth sample collection in this study conformed to exempt protocols approved by the Institutional Review Board of University of Tennessee Health Science Center (12-01937-XM). Molars were vertically split into mesial and distal roots by using a water-cooled high-speed bur. Only distal roots with single canals were used in this study. The configuration of the single canal was confirmed through high magnification and buccolingual and mesiodistal radiographs. Composite resin was used to build the remaining walls of the coronal portion of the tooth crown to provide a reservoir for the irrigant. The crowns of the teeth were adjusted to a standardized working length of $18 \mathrm{~mm}$. Canals were instrumented by using rotary files up to 25/04 (Endo Sequence; Brasseler) while maintaining apical patency. Teeth were then autoclaved in PBS at $121^{\circ} \mathrm{C}$ for 20 minutes.

\section{Canal Inoculation with Enterococcus faccalis}

A standard suspension $\left(1 \times 10^{8}\right.$ cells $\left./ \mathrm{mL}\right)$ of $E$. faecalis (ATCC 47077; Rockville, MD) was prepared from a 24-hour culture of bacteria grown in brain heart infusion (BHI; Difco). Each canal was filled to the orifice level with $E$. faecalis suspension by using sterile $1-\mathrm{mL}$ insulin syringes with a 30-gauge needle. The root was then placed in a 15$\mathrm{mL}$ tube containing $10 \mathrm{~mL}$ BHI broth and incubated at $37^{\circ} \mathrm{C}$ for 21 days in $100 \%$ humidity to allow colonization of the bacteria on the canal wall and into the dentinal tubules. Aliquots of culture medium $(5.0 \mathrm{~mL})$ were replaced with fresh medium every 3 days.

\section{Disinfection Procedures}

After 21 days, specimens were removed from the inoculation tubes, and the root apexes were sealed with composite resin in a clean environment laminar flow cabinet to prevent sample contamination. The canals were disinfected by using 4 different irrigation systems/groups described below (15 teeth/group). In each procedure, the canals were irrigated with $2 \mathrm{~mL} \mathrm{17 \%} \mathrm{EDTA} \mathrm{for} 1$ minute by using a 30-gauge side-vented needle, followed by $3 \mathrm{~mL} 6 \%$ $\mathrm{NaOCl}$ at a flow rate of $2 \mathrm{~mL} / \mathrm{min}$ with the following cycles: $30 \mathrm{sec}-$ onds of $6 \% \mathrm{NaOCl}$ irrigation $(1 \mathrm{~mL} / 30 \mathrm{sec})$ followed by 30 seconds of no irrigation. Procedures were performed by one board-certified endodontist except for the PIPS group. Below are the different treatment protocols.

Group 1: SNI. A 30-gauge side-vented needle was placed within $2 \mathrm{~mm}$ from the working length and moved in a vertical motion to avoid the needle being locked in the canal. To ensure length control, a stopper was placed on the needle at the required length.

Group 2: EA. The canal was first passively filled with irrigant. The irrigation needle was then placed at the pulp chamber level, and under con- stant irrigation, a yellow EA tip was placed in the canal $1 \mathrm{~mm}$ short of the working length, and irrigant was activated by following the method described above.

Group 3: XP Endo. In a manner similar to EA, the file was placed $1 \mathrm{~mm}$ short of the working length and operated by using a slowspeed motor at 900 RPM in a vertical motion. Similar to SNI, a stopper was adjusted at the required length for length control.

Group 4: PIPS. Fotona LightWalker Er:YAG (Fotona LLC, Dallas, TX) was set at the recommended settings $(20 \mathrm{~mJ}, 15 \mathrm{~Hz}, 0 / 0$ air/water). For this part of the study, a clinician with experience in using PIPS operated the instrument. The canal was first passively filled with irrigant as described above, and under constant irrigation, the PIPS tip was placed in the pulp chamber and was submerged in irrigant as described previously (14). The tip was left stationary and activated for the cycles described under constant irrigation, while ensuring the canal and pulp chamber remained passively filled with irrigant throughout irrigation. If the pulp chamber was seen without irrigant, the cycle was stopped and then continued after replenishing the pulp chamber with $\mathrm{NaOCl}$.

\section{E. faecalis Sampling}

After the 21-day bacterial incubation, $E$. faecalis in the root canal of each tooth was sampled before (S1) and after (S2) disinfection. All materials and instruments used in the following sample collection were sterile. For collection of S1 samples, the BHI broth in the canal space was first aspirated and then filled with PBS. A Hedström instrument \#25 was used to file the dentinal walls vigorously (20 strokes). Canal content was then aspirated by using $1-\mathrm{mL}$ insulin syringes with a 25 -gauge needle and transferred to a microcentrifuge tube. This procedure was repeated 3 times/canal, and the final volume of collected bacteria in PBS was $100 \mu \mathrm{L}$ for each tooth/canal. After S1 sample collection, each tooth/canal was disinfected by one of the disinfection methods described above, followed by flushing the root canal with $1 \mathrm{~mL} \mathrm{10 \%} \mathrm{sodium} \mathrm{thiosulfate} \mathrm{to} \mathrm{neutralize} \mathrm{the} \mathrm{NaOCl.} \mathrm{The} \mathrm{canal}$ was then ready for S2 sample collection. Each canal was treated and bacterial samples were collected with the same manner as that for $\mathrm{S} 1$ sample collection.

\section{MTT Assay}

Collected bacterial samples ( $\mathrm{S} 1$ and $\mathrm{S} 2$ ) from the canals were subjected to a standard MTT assay to detect the viable bacteria. Ten microliters of 3-[4,5-dimethylthiazol-2-yl]-2,5-diphenyltetrazolium bromide (MTT) agent (Sigma-Aldrich, St Louis, MO) was placed in each of the microcentrifuge tubes containing the bacteria samples. Samples were vortexed and then incubated at $37^{\circ} \mathrm{C}$ for 4 hours. Then $110 \mu \mathrm{L}$ isopropanol/HCl was added to each tube to solubilize the formazan dye. Microcentrifuge tubes were then spun for 5 minutes at $6000 \mathrm{RPM}$, and $190 \mu \mathrm{L}$ supernatant was placed in a 96-well plate. The optical density was read at $570 \mathrm{~nm}$ by using a SpectraStar Nano spectrometer (BMGLabTech, Ortenberg, Germany). Two blanks (PBS only) were included for each group as a negative control. Two samples in the PIPS group were excluded because of errors during sampling.

\section{CISM}

To study the ability of each disinfection method to eliminate/ kill bacteria in the dentinal tubules, we used CLSM to directly visualize the live/dead bacteria in the tubules. Eighteen intact mandibular premolars were used for this part of the study. Teeth were instrumented, autoclaved, and then inoculated with $E$. faecalis for 21 days and disinfected with the above-mentioned procedures 


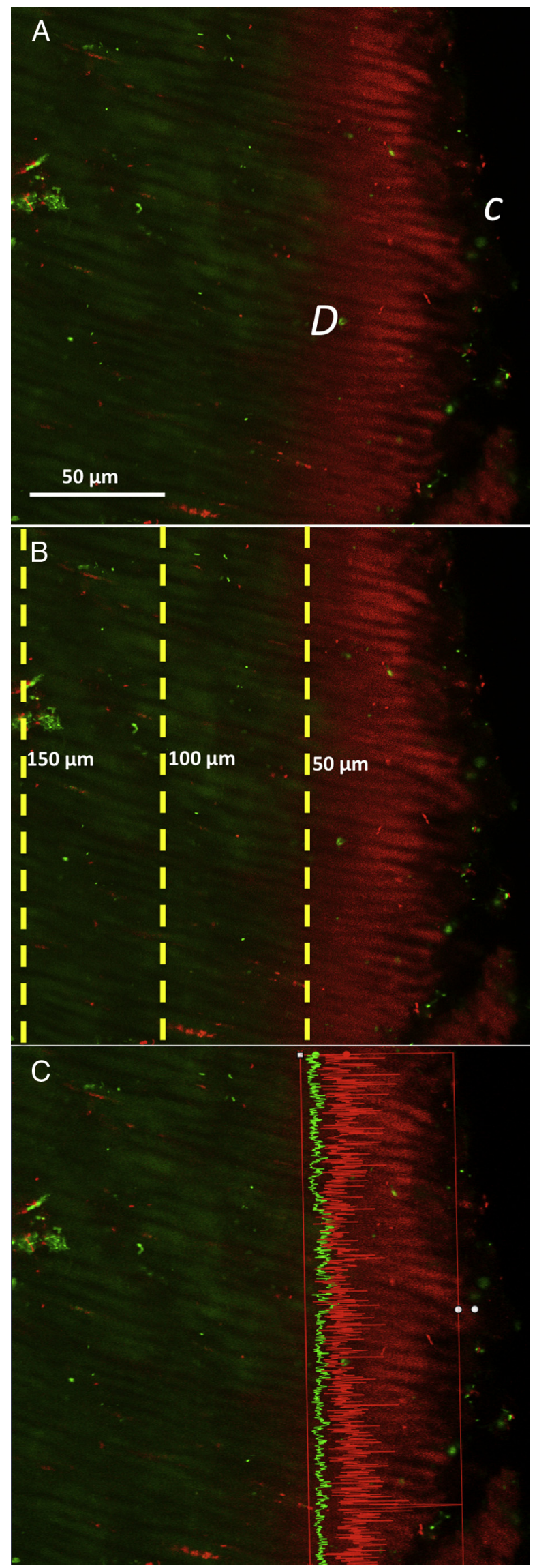

and techniques (4 teeth/group). Two teeth served as controls. After the 21-day bacterial inoculation, 1 tooth was autoclaved and used as a negative control. The other tooth did not receive canal disinfection and was used as a positive control. Teeth were then decoronated, and the roots were split vertically into 2 halves as described by Al Shahrani et al (14). Briefly, a groove was cut along the long axis of the tooth without penetrating the root canal system. By using a chisel, the root was split open into 2 pieces. All samples were visually inspected to select 1 sample from each group with comparable canal dimensions for CLSM analysis. Samples were then stained by using LIVE/DEAD BackLight Bacterial Viability Kit (Molecular Probes, Inc, Eugene, OR) for 15 minutes, according to the manufacturer's instructions. A Zeiss LSM 510 confocal microscope (Carl Zeiss, Oberkochen, Germany) set at the excitation/ emission wavelengths of $480 / 500 \mathrm{~nm}$ for SYTO 9 and 490/ $635 \mathrm{~nm}$ for propidium iodide was used to inspect the tooth samples $(\times 20$ with an additional $\times 2$ zoom). CLSM images were acquired by the software Zen V. 2 (Carl Zeiss) at a resolution of $1024 \times 1024$ pixels.

\section{CISM Analysis}

We used a method similar to that described by Ma et al (20). Three random locations on the root were scanned at each part, coronal, middle, and apical (total of 9 images/tooth), at 10- $\mu$ m-deep scans (1- $\mu \mathrm{m}$ step size, 10 slices/scan; each scan took $\sim 20$ minutes). The 10 slices of images were then stacked into 1 image (ie, each image represented 10 slices/scan area). For each stacked image, 3 measurements were taken, representing 3 different depth levels: $50 \mu \mathrm{m}, 100 \mu \mathrm{m}$, and $150 \mu \mathrm{m}$ deep into the dentinal tubules as displayed in Figure 1. All the scanned points along the dashed line of the particular depth level were measured by Zen 2 software (Zeiss). At each depth level, the software measured the intensities of red (dead bacteria) and green fluorescence (live bacteria), eg, at $50-\mu \mathrm{m}$ level as shown in Figure $1 C$, the red fluorescence intensity is higher than green. The measured red/green fluorescence intensities were used to calculate the percentage of dead bacteria over both dead and live bacteria.

\section{Statistical Analysis}

For MTT assay, the approximated bacterial reduction was calculated for each group by using the following formula:

$$
\text { Bacterial reduction percentage }=\frac{S 1-S 2}{S 1} \times 100 \%
$$

Shapiro-Wilk test was performed to determine whether the samples were normally distributed by groups. Because the data were not normally distributed, Kruskal-Wallis test was used to test the overall difference among groups. Dwass-Steel-Critchlow-Fligner multiple comparison procedure was used to perform the pairwise comparison.

For CLSM analyses, the percentage of red to red-green combined was calculated for each group:

Figure 1. Method of confocal imaging analysis of live/dead bacteria in dentinal tubules. $(A)$ Representative image after image stacking showing the canal side $C$ and dentin side $D$, revealing dead bacteria (red) and live bacteria (green). (B) At different depth planes within the dentinal tubules, measurements were taken at 50,100, and $150 \mu \mathrm{m}$ deep into the dentinal tubules. $(C)$ Representative image profiling on ZEN software showing measurement of red and green fluorescence intensities along the line at 50- $\mu \mathrm{m}$ depth level. 


$$
\text { percent }=\frac{\text { intensity of red }}{\text { intensity of red }+ \text { intensity of green }} \times 100
$$

Three factors of analysis of variance were fit by using treatment groups (SNI, EA, XP Endo, or PIPS), locations (coronal, mid-root, or apical), and depth points $(50 \mu \mathrm{m}, 100 \mu \mathrm{m}$, or $150 \mu \mathrm{m})$ as factors. Pairwise comparisons were performed by using tests of contrasts between the tested groups at different locations and depth points. Tukey-Kramer method was used to control experiment-wise type I error rate at 0.05 .

SAS 9.4 (SAS Institute, Inc, Cary, NC) software was used for all analyses. The difference was considered to be significant when the $P$ values were less than .05 .

\section{Results}

\section{Bacterial Elimination Efficiency in Ganal Space}

The MTT assay measured the viable bacteria from the sample collection before and after root canal disinfection. Results are displayed in Figure 2. The median percentage reduction ranged between $89.6 \%$ and $98.2 \%$ relative to $\mathrm{S1}$. Pairwise comparison showed statistically significant difference in the bacterial reduction efficiency between XP Endo and PIPS $(P<.05)$ as well as between XP Endo and EA $(P<.05)$. There was no significant difference in the bacterial reduction between SNI, PIPS, and EA $(P>.05)$.

\section{Efficiency of Killing Bacteria in Dentinal Tubules}

We applied CLSM to detect live versus dead bacteria in the dentinal tubules after staining. As shown in Figure 3, representative images depict live/dead bacteria in the dentinal tubules of different segments (coronal, middle, and apical) in roots treated by the 4 disinfection procedures. The negative control showed no live bacteria in the dentinal tubules, whereas dead bacteria were present.

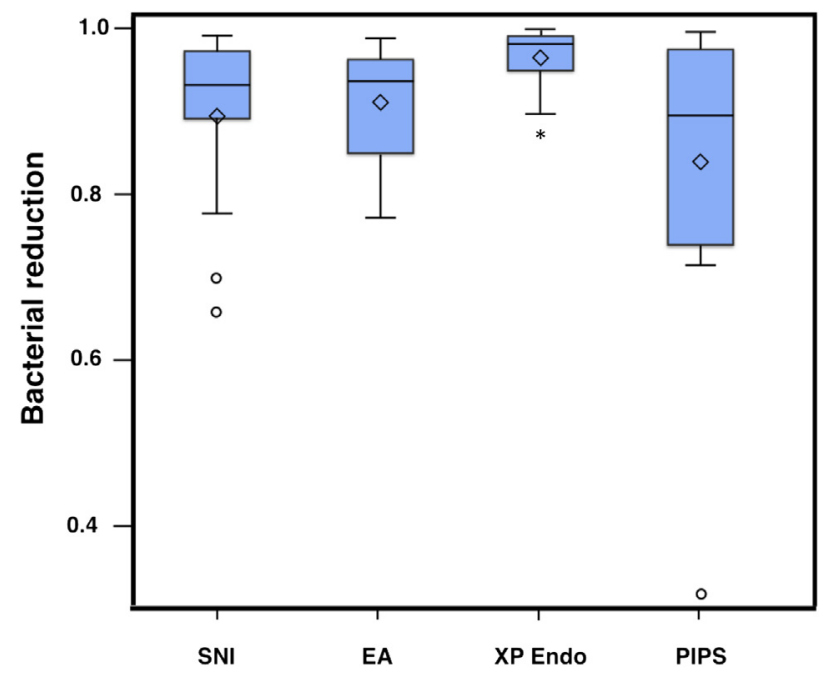

Figure 2. Efficiency of bacterial elimination in the main canal by different disinfection methods. Box plots showing level of bacterial reduction percentage by groups ( $n=15$ per group, except PIPS group $n=13$ ). Live bacteria collected from sampling before (S1) and after (S2) disinfection were detected and measured by MTT assays. Bacterial reduction levels were calculated and plotted as depicted. *Significance $(P<.05)$ compared with all other groups. Middle line in the box, median; $\diamond$, mean; $\bigcirc$, individual observations that may be potential outliers.
In contrast, the positive control had many live bacteria in the dentinal tubules.

The percentage of dead bacteria (red) over total bacteria was calculated along the vertical lines placed on each image as described in Figure 1. The measurement along the lines ranged between 2770 and 3059 points/image. The results from analyzing those images are presented in Figure 4. There was no statistically significant difference between EA and XP Endo at the 50- $\mu \mathrm{m}$ and $100-\mu \mathrm{m}$ levels in the apical segment $(P>.05)$. There was no statistically significant difference between XP Endo and SNI at the 100$\mu \mathrm{m}$ level in the mid-root segment or at the $150-\mu \mathrm{m}$ level in the apical segment $(P>.05)$. All the other groups showed a statistically significant difference between each other at every dentinal tubule depth level and canal segment (coronal, middle, and apical) $(P<.05)$. Overall, XP Endo had the highest level of dead bacteria in the coronal, middle, and apical segments at 50- $\mu \mathrm{m}$ depth. On the other hand, PIPS had the greatest bacterial killing efficiency at the $150-\mu \mathrm{m}$ depth in all 3 root segments.

\section{Discussion}

This study compared 4 different irrigation protocols in their abilities to eliminate bacteria in the root canal space as well as their lateral penetration capabilities into the dentinal tubules to kill bacteria. The study presents a novel method to analyze CLSM images that allowed us to calculate the percentage of dead bacteria in the dentinal tubules at coronal, middle, and apical segments of the canal and at different depths into the tubules. The data reflect the levels of efficiency of the different irrigation protocols tested in killing the bacteria that colonized deep into the dentinal tubules.

E. faecalis was chosen for our present study because it has been repeatedly isolated from the root canal system in failing endodontic cases (22-24). In addition, E. faecalis can penetrate into the dentinal tubules $(25,26)$ and form biofilms, which are more resistant to canal disinfection $(27,28)$. Previous studies that used CLSM either did not quantify the dead bacteria (14-16) or only quantified the dead bacteria across the entire image (20). In addition, samples were always selected from the coronal and middle thirds of the canal but not the apical third (20). Although the apical third has more peritubular dentin and a decreased number of dentinal tubules (29), peritubular dentin was observed only in the apical $0-1.3 \mathrm{~mm}$ of the canal (30). At levels coronal to that $(1.5-3 \mathrm{~mm})$, tubular dentin can still be observed. Our present study addressed this issue by using CLSM imaging analysis capacity to compare the percentage of dead bacteria up to $150 \mu \mathrm{m}$ deep into the dentinal tubules at the coronal, middle, and apical thirds of the canal.

For bacterial reduction efficiency in the main canal space, XP Endo showed a significantly higher bacterial reduction (98.2\%) compared with PIPS (89.6\%) and EA (93.3\%). In terms of the efficiency of killing the bacteria in dentinal tubules, XP Endo treated teeth also showed the highest percentage of dead bacteria at a 50$\mu \mathrm{m}$ depth in the coronal, middle, and apical thirds of the canal, ranging between $78 \%$ and $82 \%$. It may have been that mechanical effects of the file during operation together with its irrigation agitation facilitated the removal of bacteria on the canal wall and killing of the bacteria at a depth of $50 \mu \mathrm{m}$. However, this ability dropped in the middle and apical thirds at the 100- $\mu \mathrm{m}$ and $150-\mu \mathrm{m}$ levels in comparison with PIPS $(P<.001)$. The results agree with Pedullà et al (18) and Brito et al (19) that there is no significant difference between PIPS or EA and SNI in bacterial reduction in the main root canal space. The results disagree with other studies in which the 
A -Ve control

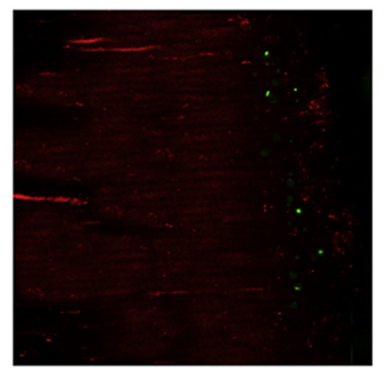

B Coronal

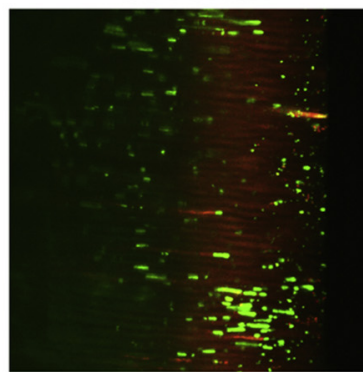

Middle

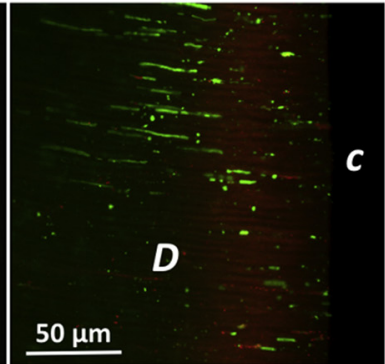

+Ve control
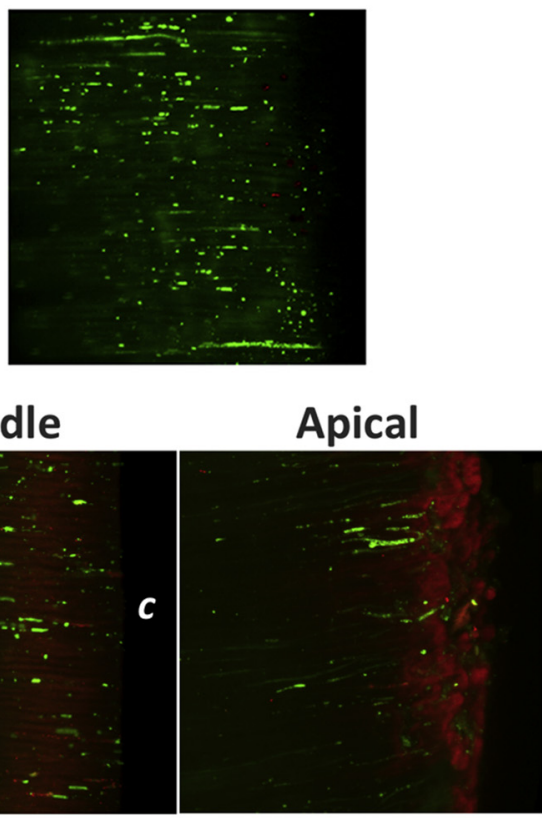

SNI

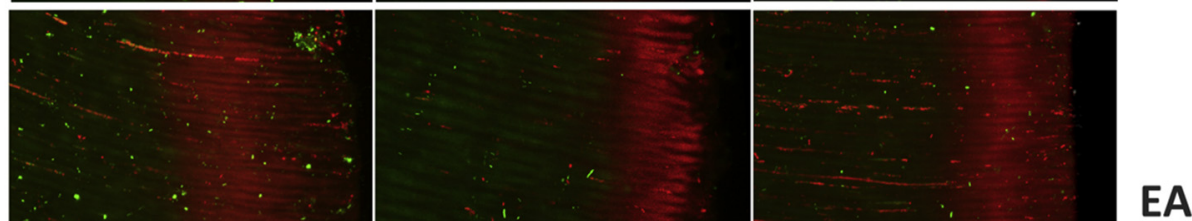

EA

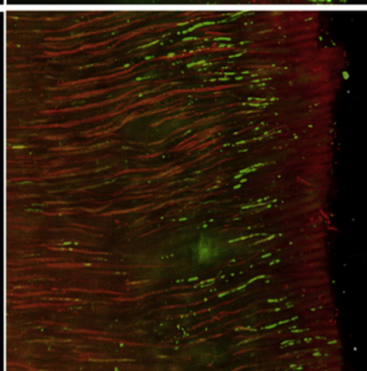

XP

Endo

PIPS

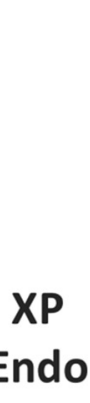

Figure 3. CLSM analysis of live/dead bacteria in dentinal tubules. (A) Positive and negative control sample images. Red indicates dead bacteria ( - Ve control), and green indicates live bacteria (+Ve control) in dentinal tubules. Negative control was inoculated as for experimental samples and then autoclaved; positive control was inoculated but not disinfected. $(B)$ Representative stacked images from coronal, middle, and apical thirds of the root showing dentinal tubules in samples treated by different irrigation methods: SNI, EA, XP Endo, and PIPS. C, canal side; D, dentin.

bacteria collected from the root canal were plated to form colonies so that the number of viable bacteria recovered was counted. Such a method yielded a result that showed a higher efficiency in disinfecting the root canal by PIPS than SNI $(14,31)$. Difference in results may stem from difference in canal size and selection of the tooth model between the studies. PIPS provided the maximum bacterial reduction 

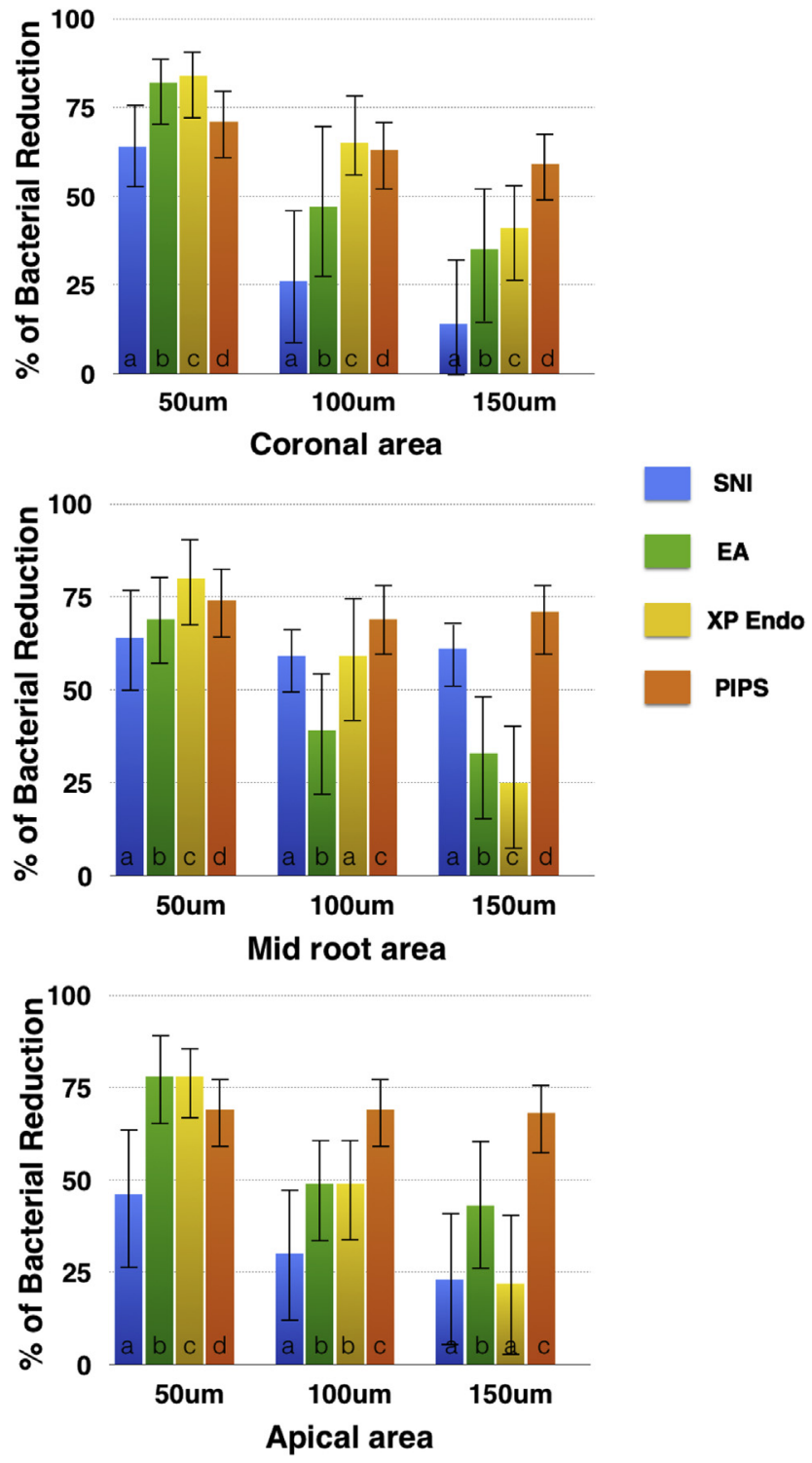

Figure 4. Quantitative analysis of dead bacteria in dentinal tubules detected by CLSM. Graphs showing percentage of dead bacteria at coronal, middle, and apical thirds of the canal at different depths into the dentinal tubules by using different canal irrigation techniques. Different letters ( $a, b, c$, and $d)$ indicate significance within each depth group.

within the dentinal tubules, ranging between $60 \%$ and $70 \%$ at the $150-\mu \mathrm{m}$ level along the entire canal length $(P<.0001)$. Such superior performance may be attributed to the cavitation bubbles produced by PIPS generating a shock wave effect, which allowed a deeper penetration of $\mathrm{NaOCl}$ into the dentinal tubules, thus creating better disinfection (17).

In this study, dead bacteria were observed in samples of all irrigation groups at different depths in dentinal tubules and segments of the root where we examined. The results agree with Zou et al (21) that $\mathrm{NaOCl}$ can manage to penetrate deeply into the dentinal tubules. However, the percentage of dead bacteria decreased at deeper levels of tubules. Each irrigation protocol showed different effectiveness in killing bacteria at different segments within the root canal system. PIPS provided a steady performance along the entire canal length and depth. XP Endo had the maximum bacterial reduction at the coronal segment, followed by mid-root and then the apical segment. On the other hand, EA had an improved performance at the apical third in comparison with mid-root, which may be attributed to the maximum oscillation of the amplitude (antinode) formed at the activator tip located in the apical third of the canal (13). On the contrary, SNI had its best disinfection at the mid-root segment. This may stem from the increased irrigant velocity as it leaves the irrigation needle and flows coronally (32), allowing deeper penetration and disinfection at the mid-root segment. As the velocity drops, its penetration efficiency is reduced at the coronal area.

In conclusion, our present study provides insight into the killing abilities of the bacteria colonized in the main canal space or that have penetrated into the dentinal tubules throughout the canal length by various clinical disinfection protocols. XP Endo appears to be stronger than PIPS and EA in disinfecting the main root canal space and up to 50 $\mu \mathrm{m}$ deep into the dentinal tubules. PIPS appears to be more effective than XP Endo and EA in deeper disinfection of the dentinal tubules. Combination of most efficient canal disinfection protocols will likely yield better endodontic outcomes, particularly in the cases for regenerative approaches. Further studies are required to determine their efficiency in different canal anatomies and larger canal models.

\section{Acknowledgments}

The authors thank Margret Jefferson (Bioscience Research, UTHSC) for her technical assistance on the spectrometer, Dr Chad Edwards (Franklin, TN) for the PIPS operation, and Dr Kristen M. S. O'Connell (Department of Physiology, UTHSC) for ber technical instruction on the use of CLSM.

This work was supported in part by a grant from the National Institutes of Health R01 DE019156 (G.T.-J.H.), a Research Fund from the University of Tennessee Health Science Center (G.T.-J.H.), and a Clinical and Translational Science Award (CTSA) from the National Center for Advancing Translational Sciences of the National Institutes of Health (UL1TR001412).

The authors deny any conflicts of interest related to this study.

\section{References}

1. Shuping GB, Orstavik D, Sigurdsson A, Trope M. Reduction of intracanal bacteria using nickel-titanium rotary instrumentation and various medications. J Endod 2000;26:751-5.

2. Dutner J, Mines P, Anderson A. Irrigation trends among American Association of Endodontists members: a web-based survey. J Endod 2012;38:37-40.

3. Ng YL, Mann V, Gulabivala K. A prospective study of the factors affecting outcomes of nonsurgical root canal treatment: part 1-periapical health. Int Endod J 2011;44: 583-609.

4. Peters OA, Laib A, Gohring TN, Barbakow F. Changes in root canal geometry after preparation assessed by high-resolution computed tomography. J Endod 2001;27:1-6.

5. Paque F, Balmer M, Attin T, Peters OA. Preparation of oval-shaped root canals in mandibular molars using nickel-titanium rotary instruments: a micro-computed tomography study. J Endod 2010;36:703-7.

6. Sjogren U, Figdor D, Spangberg L, Sundqvist G. The antimicrobial effect of calcium hydroxide as a short-term intracanal dressing. Int Endod J 1991;24:119-25.

7. Sjogren U, Figdor D, Persson S, Sundqvist G. Influence of infection at the time of root filling on the outcome of endodontic treatment of teeth with apical periodontitis. Int Endod J 1997;30:297-306.

8. McGurkin-Smith R, Trope M, Caplan D, Sigurdsson A. Reduction of intracanal bacteria using GT rotary instrumentation, 5.25\% NaOCl, EDTA, and $\mathrm{Ca}(\mathrm{OH}) 2$. J Endod 2005:31:359-63.

9. Siqueira JF Jr, Guimaraes-Pinto T, Rocas IN. Effects of chemomechanical preparation with $2.5 \%$ sodium hypochlorite and intracanal medication with calcium hydroxide on cultivable bacteria in infected root canals. J Endod 2007;33: $800-5$.

10. Siqueira JF Jr, Magalhaes KM, Rocas IN. Bacterial reduction in infected root canals treated with $2.5 \% \mathrm{NaOCl}$ as an irrigant and calcium hydroxide/camphorated paramonochlorophenol paste as an intracanal dressing. J Endod 2007;33: $667-72$ 
11. Lin LM, Ricucci D, Huang GT. Regeneration of the dentine-pulp complex with revitalization/revascularization therapy: challenges and hopes. Int Endod J 2014;47:713-24.

12. Gu LS, Kim JR, Ling J, et al. Review of contemporary irrigant agitation techniques and devices. J Endod 2009;35:791-804.

13. Ruddle C. Endodontic disinfection: tsunami irrigation. Saudi Endodontic Journal 2015;5:1.

14. Al Shahrani M, DiVito E, Hughes CV, et al. Enhanced removal of Enterococcus faecalis biofilms in the root canal using sodium hypochlorite plus photon-induced photoacoustic streaming: an in vitro study. Photomed Laser Surg 2014;32:260-6.

15. Mathew J, Emil J, Paulaian B, et al. Viability and antibacterial efficacy of four root canal disinfection techniques evaluated using confocal laser scanning microscopy. J Conserv Dent 2014;17:444-8.

16. Koch JD, Jaramillo DE, DiVito E, Peters OA. Irrigant flow during photon-induced photoacoustic streaming (PIPS) using Particle Image Velocimetry (PIV). Clin Oral Investig 2016; 20:381-6.

17. DiVito E, Peters OA, Olivi G. Effectiveness of the erbium:YAG laser and new design radial and stripped tips in removing the smear layer after root canal instrumentation. Lasers Med Sci 2012;27:273-80.

18. Pedulla E, Genovese C, Campagna E, et al. Decontamination efficacy of photoninitiated photoacoustic streaming (PIPS) of irrigants using low-energy laser settings: an ex vivo study. Int Endod J 2012;45:865-70.

19. Brito PR, Souza LC, Machado de Oliveira JC, et al. Comparison of the effectiveness of three irrigation techniques in reducing intracanal Enterococcus faecalis populations: an in vitro study. J Endod 2009;35:1422-7.

20. Ma J, Wang Z, Shen Y, Haapasalo M. A new noninvasive model to study the effectiveness of dentin disinfection by using confocal laser scanning microscopy. J Endod 2011;37:1380-5.
21. Zou L, Shen Y, Li W, Haapasalo M. Penetration of sodium hypochlorite into dentin. J Endod 2010;36:793-6.

22. Pinheiro ET, Gomes BP, Ferraz CC, et al. Microorganisms from canals of root-filled teeth with periapical lesions. Int Endod J 2003;36:1-11.

23. Sundqvist G, Figdor D, Persson S, Sjogren U. Microbiologic analysis of teeth with failed endodontic treatment and the outcome of conservative re-treatment. Oral Surg Oral Med Oral Pathol Oral Radiol Endod 1998;85:86-93.

24. Hancock HH 3rd, Sigurdsson A, Trope M, Moiseiwitsch J. Bacteria isolated after unsuccessful endodontic treatment in a North American population. Oral Surg Oral Med Oral Pathol Oral Radiol Endod 2001;91:579-86.

25. Haapasalo M, Orstavik D. In vitro infection and disinfection of dentinal tubules. J Dent Res 1987;66:1375-9.

26. Love RM. Enterococcus faecalis: a mechanism for its role in endodontic failure. Int Endod J 2001;34:399-405.

27. Distel JW, Hatton JF, Gillespie MJ. Biofilm formation in medicated root canals. J Endod 2002;28:689-93.

28. Evans M, Davies JK, Sundqvist G, Figdor D. Mechanisms involved in the resistance of Enterococcus faecalis to calcium hydroxide. Int Endod J 2002;35:221-8.

29. Carrigan PJ, Morse DR, Furst ML, Sinai IH. A scanning electron microscopic evaluation of human dentinal tubules according to age and location. J Endod 1984;10:359-63.

30. Love RM. Regional variation in root dentinal tubule infection by Streptococcus gordonii. J Endod 1996;22:290-3.

31. Peters OA, Bardsley S, Fong J, et al. Disinfection of root canals with photon-initiated photoacoustic streaming. J Endod 2011;37:1008-12.

32. Boutsioukis C, Lambrianidis T, Kastrinakis E. Irrigant flow within a prepared root canal using various flow rates: a computational fluid dynamics study. Int Endod J 2009; 42:144-55. 